\title{
Putative anti-inflammatory, antioxidant, and anti-apoptotic roles of the natural tissue guardian methyl palmitate against isoproterenol-induced myocardial injury in rats
}

Ahmed B. Hamed ${ }^{1 *}$, Eman M. Mantawy², Wesam M. El-Bakly ${ }^{3}$, Yousra Abdel-Mottaleb ${ }^{1}$ and Samar S. Azab ${ }^{2}$

\begin{abstract}
Background: Myocardial injury is considered as a worldwide main cause of morbidity and mortality. The present study aimed to investigate the probable cardioprotective activity of the naturally occurring endogenous fatty acid ester methyl palmitate (MP) against isoproterenol (ISO)-induced myocardial injury in rats and the possible underlying molecular mechanisms. The study was carried out in two consecutive sets of experiments; the first set screened the cardioprotective dose of MP in ISO-intoxicated rats. In the second set, forty male Sprague Dawley rats received either MP (150 mg/kg, p.o) three times/week for 2 weeks and/or 2 consecutive doses of ISO separated by $24 \mathrm{~h}(85 \mathrm{mg} / \mathrm{kg}, \mathrm{s.c})$ on the 13th and 14th days. Different cardiotoxicity and oxidative stress markers were assessed. Furthermore, endothelial nitric oxide synthase (eNOS) levels were determined. For detection of apoptosis, Bax, Bcl-2, and caspase 3 were estimated. To assess inflammation, toll-like receptor 4 (TLR-4) and tumor necrosis factor-alpha (TNF-a) were measured using ELISA. Meanwhile, nuclear factor kappa B (NF-kB) and cyclooxygenase-2 (COX-2) were detected immunohistochemically.
\end{abstract}

Results: Pretreatment with MP significantly ameliorated the cardiotoxicity and oxidative stress markers. It also markedly elevated eNOS content, decreased apoptotic marker expression, and mitigated TLR-4 activation and other inflammatory markers. Electrocardiography and histopathological examination also confirmed the cardioprotective effect of MP.

Conclusion: The findings of this study indicated that MP possesses a potent cardioprotective activity against ISOinduced myocardial injury through its significant antioxidant, anti-apoptotic, anti-inflammatory, and vasodilatation activities.

Keywords: Myocardial injury, Methyl palmitate, ISO, Oxidative stress, eNOS, Apoptosis, TLR-4, Inflammation

\footnotetext{
* Correspondence: ahmed.badreldin@fue.edu.eg

'Pharmacology, Toxicology and Biochemistry Department, Faculty of Pharmaceutical Sciences and Pharmaceutical Industries, Future University in Egypt, End of 90th St., 5th Settlement, New Cairo, Cairo 11835, Egypt Full list of author information is available at the end of the article
}

Springer Open
(๑) The Author(s). 2020 Open Access This article is licensed under a Creative Commons Attribution 4.0 International License, which permits use, sharing, adaptation, distribution and reproduction in any medium or format, as long as you give appropriate credit to the original author(s) and the source, provide a link to the Creative Commons licence, and indicate if changes were made. The images or other third party material in this article are included in the article's Creative Commons licence, unless indicated otherwise in a credit line to the material. If material is not included in the article's Creative Commons licence and your intended use is not permitted by statutory regulation or exceeds the permitted use, you will need to obtain permission directly from the copyright holder. To view a copy of this licence, visit http://creativecommons.org/licenses/by/4.0/. 


\section{Background}

Myocardial injury is known to be one of the most common reasons of morbidity and mortality all over the world [1]. Although numerous medicinal and interventional treatments for myocardial injury were significantly enhanced recently, many patients develop poor prognosis which leads to reduced quality of life and elevated mortality risk [2]. Among myocardial injury morbidities, myocardial ischemia is considered as a major cause of cardiovascular deaths [3]. Prolonged myocardial ischemia results in necrosis of cardiomyocytes because of the abruption of the blood flow to a part of the myocardium [4].

Isoproterenol [1-(3, 4-dihydroxyphenyl)-2-isopropylamino ethanol hydrochloride] (ISO), is one of the synthetized catecholamines which stimulate $\beta$-adrenoceptors [3]. Activation of $\beta 1$-adrenoceptors plays a major role in the disturbance of the myocardial contraction and energy metabolism during stress conditions resulting in the progression of cardiac remodeling and failure [5].

Induction of myocardial injury by ISO serves as an ideal-standardized experimental model for studying the useful effects of numerous drugs and heart functions as ISO-induced cardiac aberrations in the experimental animals closely mimics the pathogenesis mechanisms in humans [6]. High doses of ISO, within the range of 85$300 \mathrm{mg} / \mathrm{kg}$, were reported to induce diffuse myocardial necrosis resulting in a progressive left ventricular dilatation and myocardial hypertrophy in rats similar to the acute myocardial ischemic injury in humans [7]. It was proven that ISO is a fundamental causative agent of severe oxidative stress within the myocardium through the production of huge amounts of cytotoxic free radicals which stimulate myocardial membrane phospholipids peroxidation resulting in serious destruction of the myocardial membrane [8].

Endothelial dysfunction is considered as a crucial event in ISO-induced myocardial injury [9]. It was reported that oxidative stress is a fundamental causative factor for endothelial dysfunction mainly due to the accelerated inactivation of nitric oxide (NO) by the reactive oxygen species (ROS) that profusely produced by ISO, which further diminishes the bioavailability of $\mathrm{NO}$ [10]. The powerful vasodilator $\mathrm{NO}$ is synthesized by endothelial nitric oxide synthase (eNOS) enzyme. It regulates the vascular tone and provides marked cardioprotection against ischemic damage [11]. It was proven that eNOS is expressed by the myocardial cells where it controls many aspects of heart functions such as heart rate and contractility [12].

Apoptosis plays a major role in the pathogenesis of ISO-induced myocardial injury [13]. The free radicals generated by ISO are known to activate the intrinsic mitochondria-dependent apoptotic pathway in the cardiomyocytes [14]. Furthermore, $\beta$-adrenergic receptor stimulation has been shown to increase the proapoptotic gene expression leading to apoptosis [15].

The inflammatory cascades have crucial roles in myocardial injury pathogenesis [16]. During myocardial injury, damage-associated molecular patterns (DAMPs) that also called alarmins are known to be released by the stressed cells undergoing necrosis acting as danger signals resulting in activation of toll-like receptors (TLRs) $[17,18]$. In this context, TLRs were reported to be upregulated in cardiac tissues in the case of myocardial injury where they trigger the production of many inflammatory mediators augmenting the myocardial tissue damage [19].

Recently, focusing on the protective roles of natural products against myocardial injury has gained a lot of attention [20]. Methyl palmitate (MP) is a naturally occurring fatty acid ester which is released in the superior cervical ganglion [21] and the retina [22] of rats. It has been reported to guard against tissue injury in various experimental models [23, 24]. Interestingly, MP is also recognized as an attenuator of macrophages including Kupffer cells [25]. These cytoprotective effects are mainly attributed to its potent antioxidant, antiinflammatory, anti-apoptotic, and vasodilatation activities [26]. The anti-inflammatory effects of MP were mainly mediated through diminishing the expression of the transcription factor nuclear factor kappa B (NF-kB) and the consequent production of pro-inflammatory cytokines [27]. It was also elucidated that MP induces vasorelaxation via its direct action on smooth muscles [28].

The target of this study is to elucidate the probable cardioprotective activity of MP against ISO-induced myocardial injury in rats and investigate the underlying molecular mechanisms.

\section{Methods \\ Drugs and chemicals}

Methyl palmitate (MP), isoproterenol (ISO), and urethane were bought from Sigma Chemical Co. (St Louis, MO, USA). Before administration, MP was dissolved in corn oil, while ISO was dissolved in normal saline. All solvents and chemicals were of the highest grade purity available.

\section{Animals}

Sixty-five male Sprague Dawley rats weighing 150-200 g were used. They were purchased from El-Nile Co., Cairo, Egypt, and housed in an air-conditioned atmosphere, at a temperature of $25^{\circ} \mathrm{C}$ with alternatively $12 \mathrm{~h}$ light and dark cycles. The standard diet and water ad libitum have been made available to the rats. Standard diet pellets (El-Nasr, Abu Zaabal, Egypt) were composed of not less than $5 \%$ fiber, $20 \%$ protein, $6.5 \%$ ash, $3.5 \%$ fat, and a 
vitamin mixture. Rats were allowed to acclimate for 2 weeks before any experimentation. All procedures and manipulations of experimental animals were carried out according to the ARRIVE guidelines and in accordance with UK Animals Act, 1986 [29], and approved by the Research Ethics Committee for experimental and clinical studies of Faculty of Pharmaceutical Sciences and Pharmaceutical Industries, Future University in Egypt, under the memorandum No.: (REC-FPSPI-9/60).

\section{Experimental design}

There were two consecutive sets of experiments for this study. The first set aimed to determine the minimum effective cardioprotective dose of MP via examining the doses 75,150 , and $300 \mathrm{mg} / \mathrm{kg}$ of MP against ISOinduced myocardial injury in rats through the assessment of the histopathological investigations and the cardiotoxicity indices. To achieve this aim, rats were randomized into five groups (5 animals each) and treated for 14 consecutive days as follows: group 1 was considered as a control group, where rats were given corn oil, p.o, three times per week at alternating days for 2 weeks. To induce myocardial injury, rats in group 2 were given corn oil, p.o, three times per week at alternating days for 2 weeks and then injected with 2 consecutive doses of ISO separated by $24 \mathrm{~h}(85 \mathrm{mg} / \mathrm{kg}$, s.c) on the 13th and 14th days [3]. Rats in groups 3,4 , and 5 were given MP in the doses 75,150 , and $300 \mathrm{mg} / \mathrm{kg}$, p.o respectively, three times per week at alternating days for 2 weeks and then injected with 2 consecutive doses of ISO separated by $24 \mathrm{~h}(85 \mathrm{mg} / \mathrm{kg}$, s.c $)$ on the 13 th and 14th days.

The consequent second set was carried out to investigate the possible underlying molecular mechanisms of the cardioprotective activity of MP using the dose of $150 \mathrm{mg} / \mathrm{kg}$ which was selected according to the results of the first set of experiments. Rats were randomized into four groups (10 animals each) and treated for 14 consecutive days as follows: group 1 was considered as a control group where rats were given corn oil, p.o, three times per week at alternating days for 2 weeks. Rats in group 2 were given MP $(150 \mathrm{mg} / \mathrm{kg}$, p.o) three times per week at alternating days for 2 weeks. Rats in group 3 were given corn oil, p.o, three times per week at alternating days for 2 weeks and then injected with 2 consecutive doses of ISO separated by $24 \mathrm{~h}(85 \mathrm{mg} / \mathrm{kg}$, s.c) on the 13th and 14th days [3]. Group 4 rats were given MP $(150 \mathrm{mg} / \mathrm{kg}$, p.o) three times per week at alternating days for 2 weeks and then injected with 2 consecutive doses of ISO separated by $24 \mathrm{~h}(85 \mathrm{mg} / \mathrm{kg}$, s.c) on the 13th and 14th days.

In both sets of experiments, rats were weighed and anesthetized with urethane $(1.2 \mathrm{gm} / \mathrm{kg}$, i.p. $) 24 \mathrm{~h}$ after the last ISO injection. Then, blood samples were obtained from the retro-orbital plexus of the rats of the first set and ECG was recorded for the rats of the second set. The sampled blood was left to clot; serum was separated by centrifugation at $3000 \mathrm{~g}$ and $4{ }^{\circ} \mathrm{C}$ for $10 \mathrm{~min}$ and kept at $-80^{\circ} \mathrm{C}$. The anesthetized rats were then sacrificed by cervical dislocation. The heart tissues were dissected, weighed, and washed with ice-cold saline. Specimens from the hearts of three rats from each group were fixed in the appropriate buffer for both histopathological assessments for the rats of the first set and immunohistochemical assessments for the rats of the second set.

In the second set of experiments, specimens from hearts of the rest seven rats of each group were homogenized in ice-cold saline using a homogenizer to obtain $10 \%(\mathrm{w} / \mathrm{v})$ heart homogenate and centrifuged at $3000 \mathrm{~g}$ and $4{ }^{\circ} \mathrm{C}$ for $10 \mathrm{~min}$, then the supernatant was collected and kept at $-80^{\circ} \mathrm{C}$ prior to analysis.

\section{Histopathological assessment of myocardial injury}

Heart autopsy samples of rats of the first set were obtained, washed, subjected to dehydration using alcohol, cleared in xylene, and embedded in paraffin at $56^{\circ} \mathrm{C}$ hot air oven for $24 \mathrm{~h}$. They were stained by hematoxylin and eosin (H\&E) for histopathological examination using a light microscope (Olympus BX-50 Olympus Corporation, Tokyo, Japan).

To obtain a range of histological myocardial injury, histopathological findings were classified into the following degrees: (0) no change, (1) mild-focal myocytes damage or small multifocal degeneration with slight degree of inflammation, (2) moderate-extensive myofibrillar degeneration and/or diffuse inflammatory process, and (3) severe-necrosis with diffuse inflammatory process [30].

\section{Assessment of cardiotoxicity indices}

Serum creatine kinase myocardial band (CK-MB), aspartate aminotransferase (AST), and lactate dehydrogenase (LDH) enzyme activities were detected spectrophotometrically using colorimetric kits (Biodiagnostics, Giza, Egypt). Heart index was calculated according to the equation: (heart weight/body weight) $\times 100$.

\section{Electrocardiography (ECG)}

The ECG instrument (CardiMax FX-7102, USA) was used for ECG recording and each recording consumed at least $10 \mathrm{~min}$. The recording rate was $25 \mathrm{~mm} / \mathrm{s}$ and the voltage was $1 \mathrm{mV} / \mathrm{cm}$. Noise reduction was performed using a digital filter. Analysis of ECG waves was performed to calculate $\mathrm{T}$ wave, heart rate (beat $/ \mathrm{min}$ ), QT interval, QTc interval by Bazett's formula $[\mathrm{QTc}=\mathrm{QT} /$ (square root of RR interval)], and QRS complex. 


\section{Assessment of oxidative stress markers}

Cardiac contents of both malondialdehyde (MDA) and reduced glutathione (GSH) and cardiac activity of superoxide dismutase (SOD) were estimated in heart homogenate using colorimetric kits (Biodiagnostics, Giza, Egypt).

Assessment of endothelial nitric oxide synthase (eNOS) Content of eNOS in heart homogenate was estimated using ELISA kits (My BioSource, Inc., USA).

\section{Assessment of apoptotic markers}

Expression of the apoptotic proteins $\mathrm{Bcl}$-2-associated $\mathrm{X}$ (Bax), B cell lymphoma 2 (Bcl-2), and caspase 3 in the heart tissues was determined immunohistochemically. Paraffin-embedded tissue sections of $3 \mu \mathrm{m}$ thickness were rehydrated first in xylene and then in graded ethanol solutions, the slides were then blocked with $5 \%$ bovine serum albumin (BSA) in tris-buffered saline (TBS) for $2 \mathrm{~h}$. After that, the sections were immunostained with the primary antibody: Bax (catalog number: PA511378), Bcl-2 (catalog number: PA5-20068), or caspase 3 (catalog number: PA1-29157) (Thermo Fisher Scientific, USA) at a concentration of $1 \mu \mathrm{g} / \mathrm{ml}$ containing $5 \%$ BSA in TBS and incubated overnight at $4{ }^{\circ} \mathrm{C}$. After washing the slides with TBS, the sections were incubated with the corresponding goat anti-rabbit secondary antibody. Washing with TBS and incubation for $10 \mathrm{~min}$ in $0.02 \%$ diaminobenzidine containing $0.01 \%$ hydrogen peroxide were then performed. Counter staining was carried out using hematoxylin, and the slides were visualized using a light microscope. The quantification of immunostaining was performed using the Image- $\mathrm{J}^{\circ}$ image analysis software (NIH, USA) and presented as the optical density of the stained sections per field $(\times 100)$.

\section{Assessment of inflammatory markers}

Toll-like receptor 4 (TLR-4) content was estimated in heart homogenate using ELISA kits (Cloud-Clone Corp., USA). Content of tumor necrosis factor-alpha (TNF- $\alpha$ ) was also detected in heart homogenate using ELISA kits (CUSABIO, USA). Nuclear factor kappa B (NF-kB) and cyclooxygenase-2 (COX-2) expression in heart tissues were further determined immunohistochemically as mentioned earlier using the primary antibody: NF-kB (catalog number: PA5-16545) or COX-2 (catalog number: PA5-17614) (Thermo Fisher Scientific, USA).

\section{Data analysis}

Data are presented as mean $\pm \mathrm{SD}$; statistical data analysis was performed using one-way ANOVA followed by Tukey as a post hoc test. The 0.05 level of probability was used as a criterion for significance. GraphPad Prism version 7 for Windows 8 (GraphPad Software, San Diego, CA, USA) was used for all statistical analysis.

\section{Results}

Prior to experimentation in both sets of experiments, all rats were observed and weighed. They were within the normal weights (150-200 g) without any observed abnormalities.

\section{Histopathological examination of heart using H\&E stain} By screening of the cardioprotective dose of MP, histopathological findings revealed normal histological structure of myocardial muscle of the control group. The muscle bundles appeared as short branched, joined to each other, and formed a network. Cross striation and oval prominent central single nuclei were observed. Myocardial fibers showed regular arrangements, clear striations, and no apparent pathological alterations. The degree of myocardial muscle damage revealed no change [(score $=0)$, (Fig. 1a) $]$.

The cardiac muscle fibers of ISO-intoxicated group showed focal areas of coagulative necrosis in which the muscle bundles appeared deeply eosinophilic with loss of its striation. Massive number of inflammatory cells' infiltration were detected in-between the necrotic muscle bundles. Disorganization of myocardial fibers was also observed. There was widespread of subendocardial necrosis accompanied by intramuscular edema. The myocardial muscle showed severe damage and necrosis with diffused inflammatory process [(score $=3$ ), (Fig. 1b)].

Histological examination of cardiac muscle tissue section of MP $(75 \mathrm{mg} / \mathrm{kg})$-pretreated group showed focal necrotic areas of deeply eosinophilic muscle bundles associated with marked intramuscular edema, inflammatory cell infiltrations, and derangement of muscle bundles. Damaged myocardial muscle with necrosis and diffuse inflammatory process was observed [(score $=2)$, (Fig. 1c)].

Histological examination of cardiac muscle tissue section of MP $(150 \mathrm{mg} / \mathrm{kg})$-pretreated group showed few inflammatory cells' infiltration, with marked preservation of myocardial bundles in contrast with ISO-intoxicated group. The myocardial muscle showed mild multifocal degeneration with slight degree of inflammation [(score $=1)$, (Fig. 1d)].

Histological examination of cardiac muscle tissue section of MP $(300 \mathrm{mg} / \mathrm{kg})$-pretreated group showed congestion of small branches of coronary blood vessels which are engorged with blood and few inflammatory cells' infiltration was also observed. The myocardial muscle exhibited mild multifocal degeneration with slight inflammatory process [(score $=1)$, (Fig. 1e)]. 


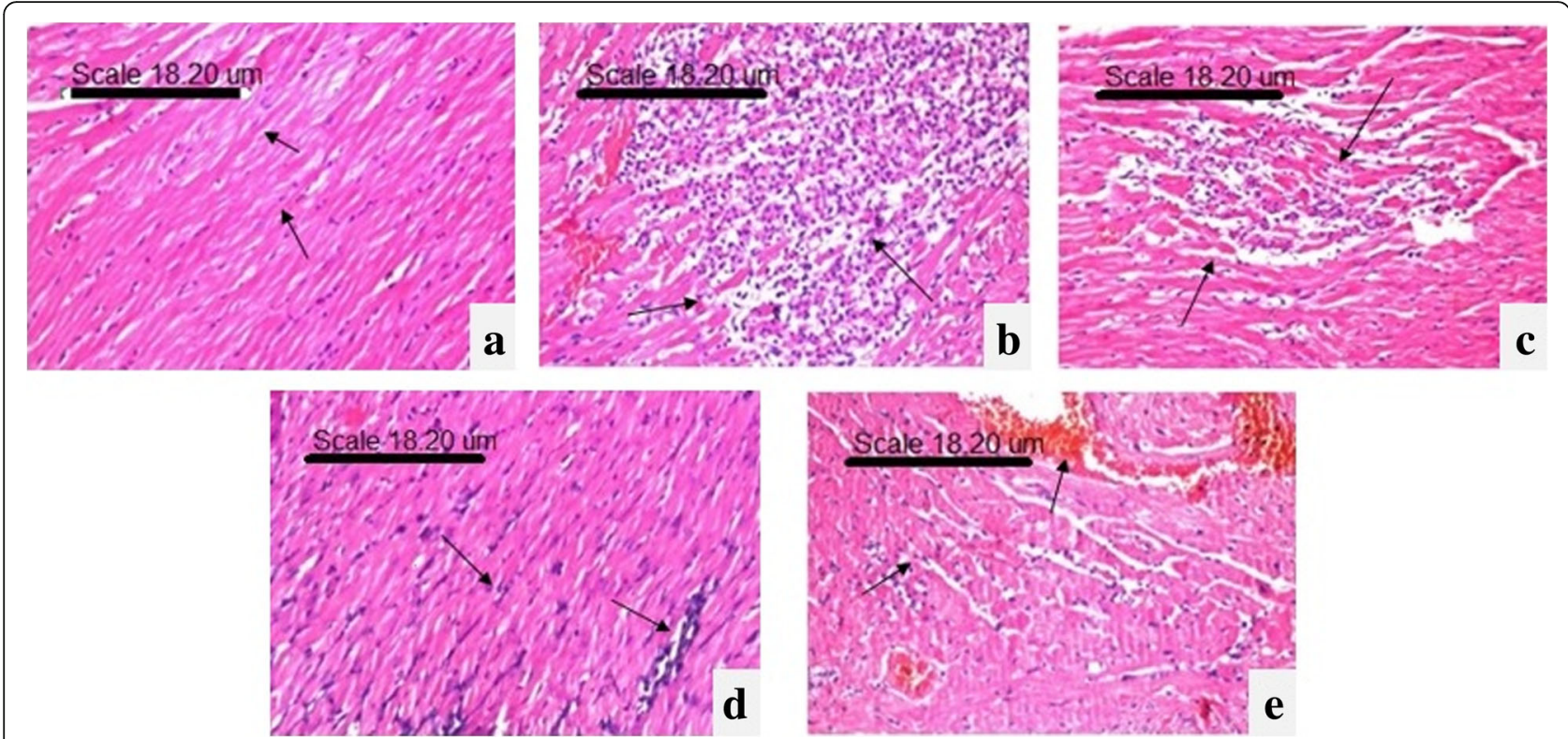

Fig. 1 Representative photomicrographs of heart sections stained by H\&E (magnification $\times 400$ ). a Control group showing normal histological structure of the myocardial bundles (arrows). $\mathbf{b}$ ISO-intoxicated group showing multiple focal areas of coagulative necrosis and massive number of inflammatory cells' infiltration (arrows). c MP (75 mg/kg)-pretreated group showing focal necrotic areas and marked inflammatory cell infiltration (arrows). d MP (150 mg/kg)-pretreated group showing cardiac muscle bundles with few inflammatory cells' infiltration (arrows). e MP (300 mg/kg)-pretreated group showing congestion of small branches of coronary blood vessels with few inflammatory cells' infiltration (arrows)

\section{Cardiotoxicity indices}

Myocardial injury induced by ISO was further confirmed by the assessment of cardiotoxicity indices. As shown in Fig. 2, ISO significantly elevated serum activities of CK$\mathrm{MB}, \mathrm{AST}$, and LDH enzymes by $39 \%, 58 \%$, and $65 \%$ respectively and increased the heart index by $28 \%$, indicating cardiac hypertrophy, as compared to the control group. In comparison with the ISO group, no significant changes were detected for MP $75 \mathrm{mg} / \mathrm{kg}$ pretreated group, while pretreatment with MP $150 \mathrm{mg} /$ $\mathrm{kg}$ significantly decreased serum activities of these cardiac enzymes by $24 \%, 28 \%$, and $34 \%$ respectively and

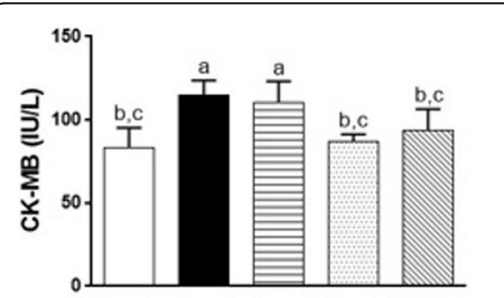

$$
\begin{aligned}
& \square \text { Control } \\
& \text { ISO } \\
& \square \operatorname{MP}(75 \mathrm{mg} / \mathrm{kg})+\text { ISO } \\
& \square \operatorname{MP}(150 \mathrm{mg} / \mathrm{kg})+\text { ISO } \\
& \square \operatorname{MP}(300 \mathrm{mg} / \mathrm{kg})+\text { ISO }
\end{aligned}
$$

\section{$\mathbf{a}$}

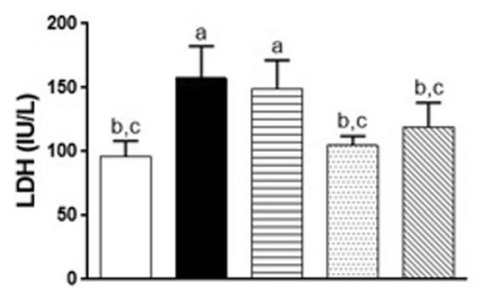

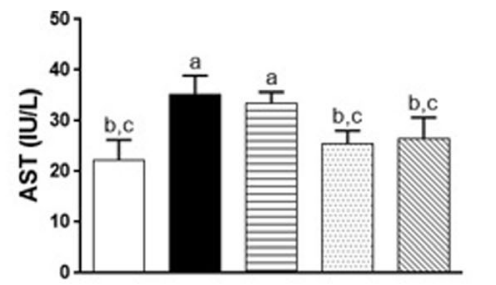

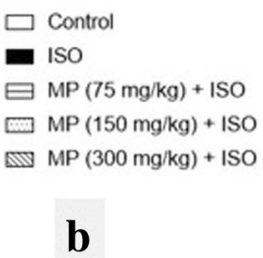

b

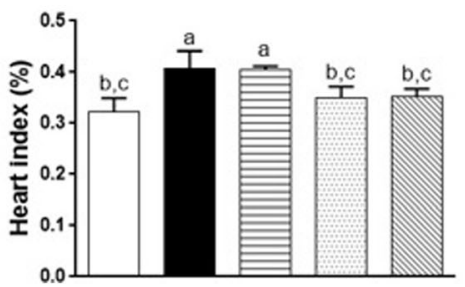

$\square$ Control

- Iso

$\boxminus \mathrm{MP}(75 \mathrm{mg} / \mathrm{kg})+1 \mathrm{SO}$

$\square \mathrm{MP}(150 \mathrm{mg} / \mathrm{kg})+\mathrm{ISO}$

WIV $\mathrm{MP}(300 \mathrm{mg} / \mathrm{kg})+1 \mathrm{SO}$

d

Fig. 2 Effect of different doses of MP on serum activities of CK-MB, AST, and LDH and heart index in ISO-intoxicated rats. a CK-MB. b AST. c LDH. d Heart index. Rats were pretreated with different doses of MP (75, 150, and $300 \mathrm{mg} / \mathrm{kg}$, p.o) three times per week on alternating days for 2 weeks and then injected with 2 consecutive doses of ISO (85 mg/ $\mathrm{kg}, \mathrm{s} . \mathrm{c})$ on the 13th and 14th days; data are presented as mean \pm SD $(n=5)$; a, b, or c: significantly different from control, ISO, or MP $75 \mathrm{mg} / \mathrm{kg}$ groups respectively at $P<0.05$ using one-way ANOVA followed by Tukey as a post hoc test. ISO isoproterenol, MP methyl palmitate, CK-MB creatine kinase myocardial band, AST aspartate aminotransferase, LDH lactate dehydrogenase 
reduced the heart index by $15 \%$. Moreover, pretreatment with MP $300 \mathrm{mg} / \mathrm{kg}$ markedly reduced the serum activities of these enzymes by $19 \%, 25 \%$, and $24 \%$ respectively and diminished the heart index by $12 \%$.

Based on the histopathological examination and the cardiotoxicity indices assessment, the middle dose of MP $(150 \mathrm{mg} / \mathrm{kg})$ showed a significant cardioprotection which was more prominent than the lowest dose $(75 \mathrm{mg} / \mathrm{kg})$, while the highest dose $(300 \mathrm{mg} / \mathrm{kg})$ did not show more protection than the middle dose. Accordingly, the dose of $150 \mathrm{mg} / \mathrm{kg}$ was the minimum effective cardioprotective dose which was selected to be used in the second set of experiments.

Since there were no significant differences between MP $(150 \mathrm{mg} / \mathrm{kg})$ only and normal control groups for the results of the second set of experiments, all comparisons for the upcoming parameters were referred to the normal control group.

\section{Electrocardiography (ECG)}

As shown in Table 1 and Fig. 3, normal cardiac activity was detected by ECG tracing for both control and MP only treated rats. On the other hand, ISO-intoxicated rats showed several marked ECG changes including inverted deep $\mathrm{T}$ wave in $80 \%$ of the intoxicated rats and significant tachycardia evidenced by the marked elevation of the heart rate by $37 \%$ as compared to the control group. Moreover, ISO intoxication showed significant prolongation of QT and QTc intervals and widening of QRS complex by $138 \%, 173 \%$, and $163 \%$ respectively as compared to the control group. Pretreatment of ISOintoxicated rats with MP effectively normalized all of the ECG changes, which evidenced by the prevention of $\mathrm{T}$ wave inversion in $90 \%$ of the pretreated rats and the significant reduction of heart rate, QT interval, QTc interval, and QRS complex by 25\%, 49\%, 50\%, and 38\% respectively as compared to ISO group.

$M P$ methyl palmitate, ISO isoproterenol, $H R$ heart rate, QT QT interval, QTc corrected QT, QRS QRS complex

\section{Oxidative stress markers}

As revealed in Fig. 4, ISO-induced oxidative stress in cardiac tissues were evaluated by measuring MDA content which was increased by $31 \%$ in the ISOintoxicated group as compared to the control group. Conversely, MP-pretreated group showed marked reduction in MDA content by $21 \%$ as compared to the ISO group. Moreover, both GSH content and SOD activity were assessed in the cardiac tissues, where ISO markedly decreased GSH content and SOD activity by $19 \%$ and $37 \%$ respectively in comparison with the control group. Meanwhile, MP-pretreated rats showed significant increase in GSH content and SOD activity by $16 \%$ and $42 \%$ respectively in comparison with the ISO group.

\section{Endothelial nitric oxide synthase (eNOS)}

The vasodilator property of MP was evaluated by the assessment of eNOS content in the cardiac tissues. As shown in Fig. 7, ISO significantly decreased eNOS content by $47 \%$ in comparison with the control group, while MP-pretreated group exhibited a significant increase in eNOS content by $57 \%$ as compared to the ISO group.

\section{Apoptotic markers}

The apoptotic tissue injury induced by ISO was assessed by the immunohistochemical examination of the proapoptotic markers Bax and caspase 3 and the antiapoptotic marker Bcl-2 expressions within the myocardium. Control and MP groups showed almost negative immunostaining for the pro-apoptotic proteins and intense immunostaining for the anti-apoptotic marker. Notably, ISO significantly elevated the expression of the pro-apoptotic protein Bax as evidenced by the intensive brown staining and markedly reduced the expression of the anti-apoptotic protein Bcl-2. Additionally, ISO showed markedly elevated expression of caspase 3 as evidenced by the intensive brown staining. On the other hand, MP pretreatment ameliorated these changes to approach the levels of the control group (Figs 5 and 6).

\section{Inflammatory markers}

The effects of ISO on inflammatory cascades were assessed by measuring the cardiac contents of TLR-4 and TNF- $\alpha$ and the cardiac expression of NF-kB and COX-2.

As illustrated in Fig. 7, ISO significantly elevated the cardiac contents of TLR- 4 and TNF- $\alpha$ by $112 \%$ and $67 \%$

Table 1 Effect of MP $(150 \mathrm{mg} / \mathrm{kg})$ on ECG pattern in ISO-intoxicated rats

\begin{tabular}{llllll}
\hline Groups & T wave inverted rats (\%) & HR (bpm) & QT (s) & QTc (s) & QRS (s) \\
\hline Control & $0(0 \%)^{\mathrm{b}}$ & $335 \pm 31^{\mathrm{b}}$ & $0.042 \pm 0.01^{\mathrm{b}}$ & $0.11 \pm 0.023^{\mathrm{b}}$ & $0.019 \pm 0.002^{\mathrm{b}}$ \\
MP (150 mg/kg) & $0(0 \%)^{\mathrm{b}}$ & $341 \pm 69^{\mathrm{b}}$ & $0.044 \pm 0.007^{\mathrm{b}}$ & $0.13 \pm 0.029^{\mathrm{b}}$ & $0.028 \pm 0.004^{\mathrm{b}}$ \\
ISO & $8(80 \%)^{\mathrm{a}}$ & $458 \pm 20^{\mathrm{a}}$ & $0.1 \pm 0.02^{\mathrm{a}}$ & $0.3 \pm 0.055^{\mathrm{a}}$ & $0.05 \pm 0.01^{\mathrm{a}}$ \\
MP (150 mg/kg) + ISO & $1(10 \%)^{\mathrm{b}}$ & $344 \pm 21^{\mathrm{b}}$ & $0.051 \pm 0.012^{\mathrm{b}}$ & $0.15 \pm 0.013^{\mathrm{b}}$ & $0.031 \pm 0.006^{\mathrm{b}}$ \\
\hline
\end{tabular}

Rats were pretreated with MP ( $150 \mathrm{mg} / \mathrm{kg}$, p.o) three times per week at alternating days for 2 weeks and then 2 consecutive doses of ISO separated by $24 \mathrm{~h}$ ( 85 $\mathrm{mg} / \mathrm{kg}, \mathrm{s.c})$ on the 13th and 14th days; data are expressed as mean \pm SD $(n=10)$, except for T wave inversions which are indicated as \%

${ }^{a}$, bignificantly different from control or ISO groups respectively at $P<0.05$ using one-way ANOVA followed by Tukey as a post hoc test 
$\mathbf{a}$

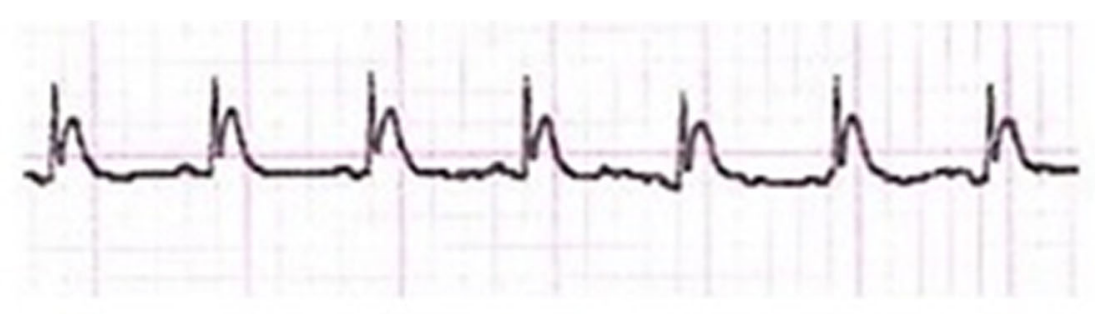

b
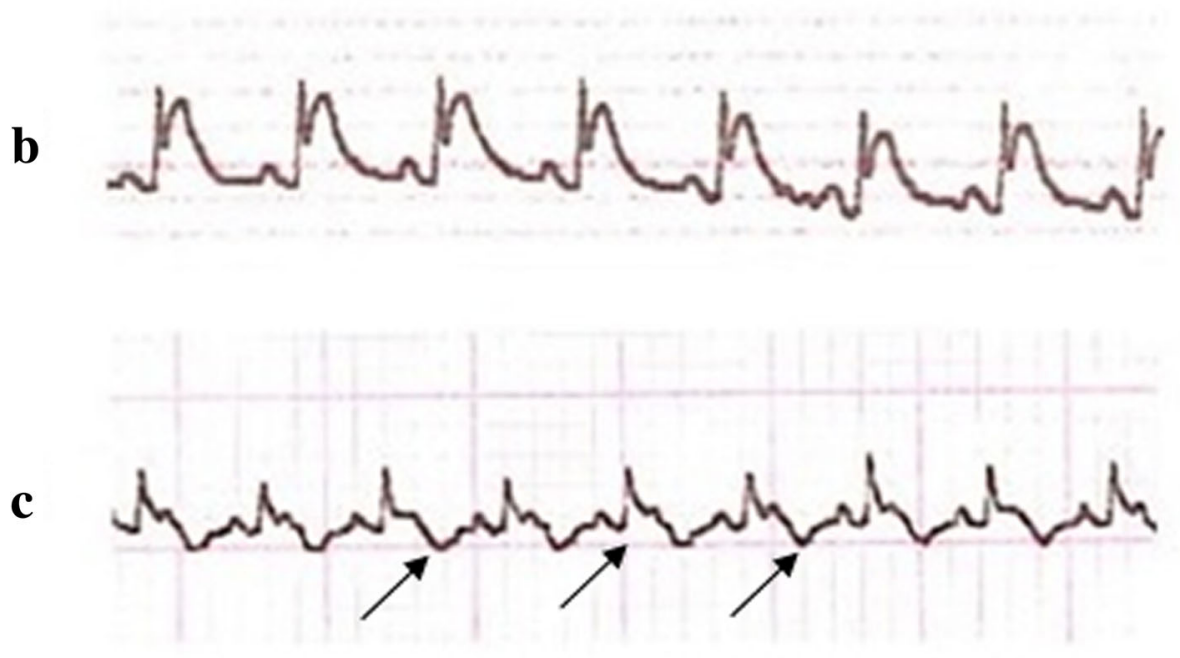

d

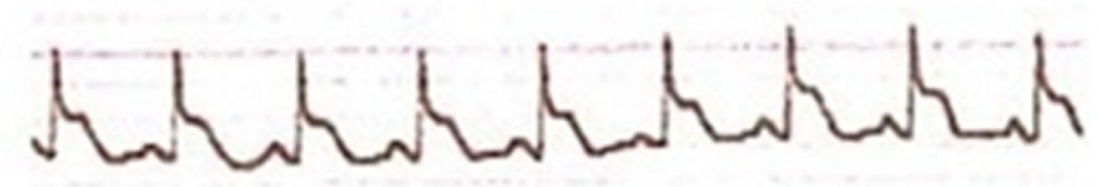

Fig. 3 Effect of MP $(150 \mathrm{mg} / \mathrm{kg})$ on ECG pattern in ISO-intoxicated rats. a Control group showing normal pattern. b MP group showing normal pattern. c ISO-intoxicated group showing inverted deep T waves, prolonged QT and QTc intervals, and widened QRS complex (arrows). d MPpretreated group showing normal pattern

respectively, in comparison with the control group. On the other hand, MP-pretreated rats showed marked amelioration of TLR- 4 and TNF- $\alpha$ contents by $27 \%$ and $32 \%$ respectively, in comparison with the ISO group.

Moreover, immunohistochemical analysis was performed for the evaluation of the cardiac expression of both transcription factor NF-kB and COX-2 enzyme, where the control and MP groups showed almost negative immunostaining for both proteins. On the other hand, ISO elevated the cardiac expression of both NF-kB and COX-2 evidenced by the intensive brown staining. Meanwhile, MP-pretreated group showed significant prevention of these increments evident by the mild immunostaining for both proteins (Fig. 8).

\section{Discussion}

The present study aimed to elucidate the potential cardioprotective activity of methyl palmitate (MP) against isoproterenol (ISO)-induced myocardial injury in rats, as well as the principal molecular mechanisms through examining its effects on various oxidative stress, apoptotic, and inflammatory markers. The study was carried out in two consecutive sets of experiments.

The results of the first set of experiments showed that ISO intoxication is associated with severe myocardial damage with multiple focal areas of coagulative necrosis, massive number of inflammatory cells' infiltration in-between the necrotic muscle bundles, disorganization of myocardial fibers, and widespread of subendocardial necrosis accompanied by intramuscular edema. Myocardial injury induced by ISO was further proven by the marked increase in the serum activities of the cardiac enzymes CK-MB, AST, and LDH. Moreover, ISO significantly increased the relative heart weight as compared to the control group reflecting cardiac hypertrophy. These findings are in 

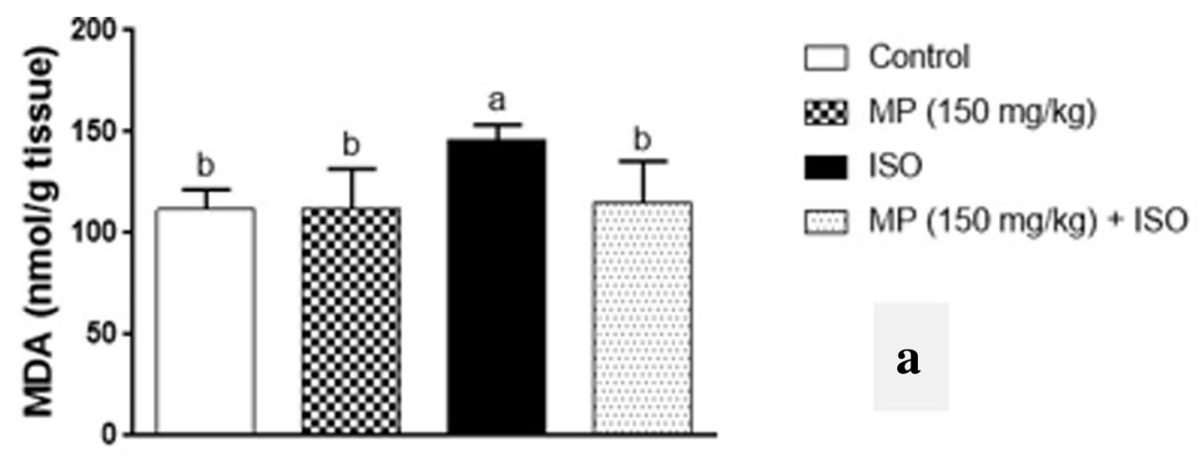

a

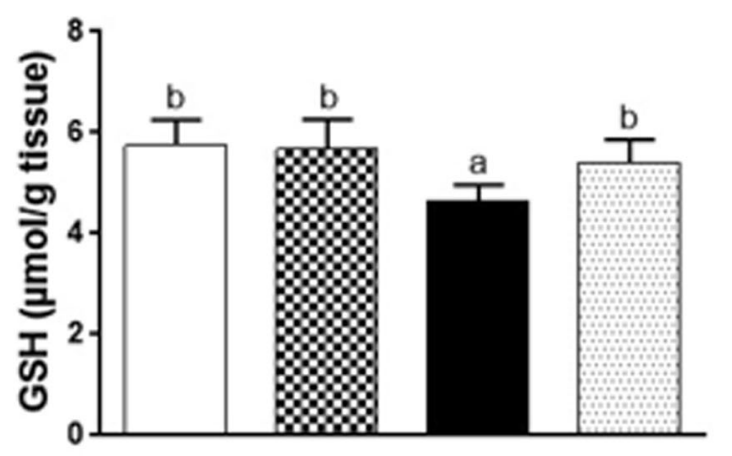

$\square$ Control

\$ MP (150 mg/kg)

- ISO

四 MP $(150 \mathrm{mg} / \mathrm{kg})+I S O$

\section{b}

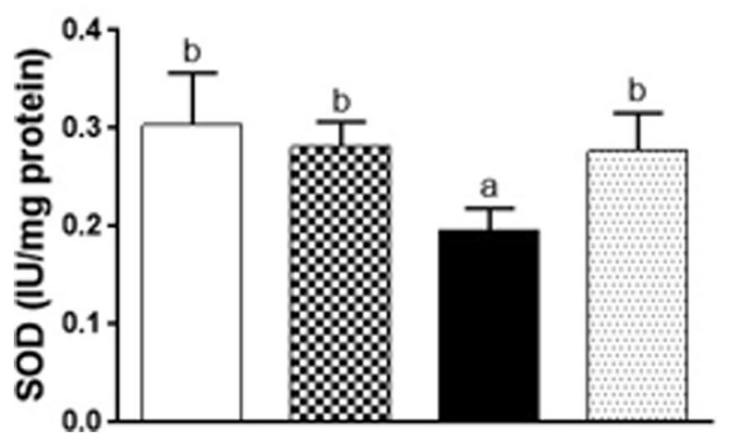

Control

\$ MP (150 mg/kg)

ISO

W. MP $(150 \mathrm{mg} / \mathrm{kg})+$ ISO

C

Fig. 4 Effect of MP (150 mg/kg) on cardiac content of MDA and GSH and cardiac activity of SOD in ISO-intoxicated rats. a MDA. b GSH. c SOD. Rats were pretreated with MP (150 mg/kg, p.o) three times per week on alternating days for 2 weeks and then injected with 2 consecutive doses of ISO (85 mg/kg, s.c) on the 13th and 14th days; data are presented as mean \pm SD ( $n=7)$; a or b: significantly different from control or ISO groups respectively at $P<0.05$ using one-way ANOVA followed by Tukey as a post hoc test. MP methyl palmitate, ISO isoproterenol, MDA malondialdehyde, GSH reduced glutathione, SOD superoxide dismutase

agreement with those of previous studies, confirming ISO cardiotoxicity [5, 31-33].

The middle dose of MP $(150 \mathrm{mg} / \mathrm{kg})$ showed a significant cardioprotective effect which was evidenced by the marked preserving of the normal architecture of the myocardium as well as the significant improvement of the serum cardiac enzyme activities and heart index. These findings are consistent with previous studies that proved the potent cardioprotective effect MP [26].

Consequently, the middle dose of MP $(150 \mathrm{mg} / \mathrm{kg})$ was selected to be used in the second set of experiments for the elucidation of the underlying molecular mechanisms of the cardioprotective activity of MP.
The chief criterion used for the definite diagnosis of myocardial injury is the evolving pattern of ECG abnormalities [34]. It was reported that inversion of $\mathrm{T}$ wave indicates the presence of myocardial ischemic injury [35]. Meanwhile, prolongation of QT interval elucidates slow ventricular conduction [34] and widening of QRS complex indicates diffused myocardial damage [36]. In this study, ISO-intoxicated group showed a significant tachycardia, inversion of $\mathrm{T}$ wave, prolongation of both QT and QTc intervals, and widening of QRS complex. Similar changes in ECG tracing in ISO-intoxicated rats have been reported in previous studies [37-39]. These abnormal changes in ECG were not noticed in animals pretreated with MP confirming its cardioprotective effect. 


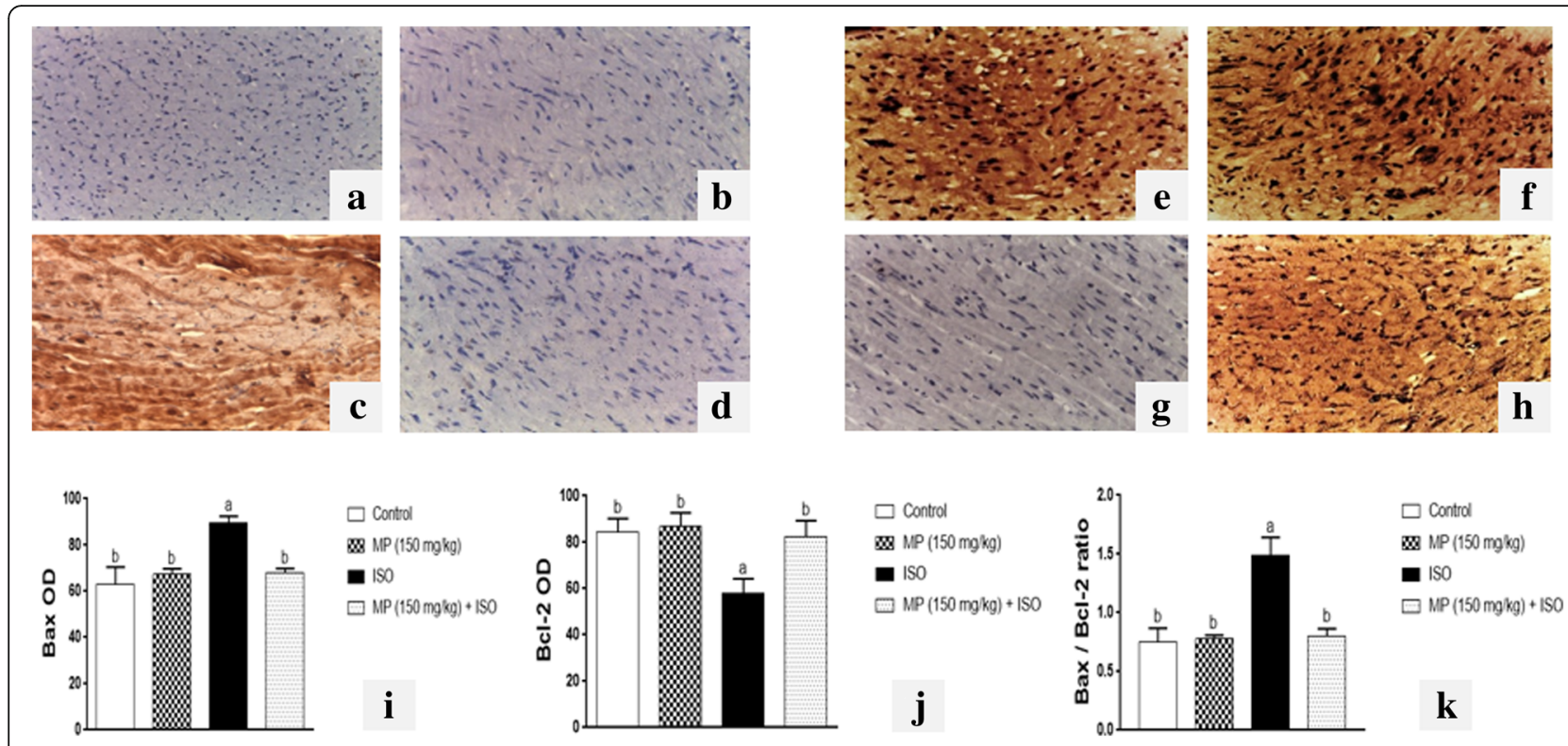

Fig. 5 Immunohistochemical analysis of Bax and $\mathrm{BCl}-2$ in heart sections (magnification $\times 400$ ). a and $\mathbf{e}$ Control group showing minimal Bax expression and maximal Bcl-2 expression respectively. $\mathbf{b}$ and $\mathbf{f} \mathrm{MP}$ group showing minimal Bax expression and maximal Bcl-2 expression respectively. $\mathbf{c}$ and $\mathbf{g}$ ISO-intoxicated group showing extensive heavy Bax expression and minimal BCl-2 expression respectively. $\mathbf{d}$ and $\mathbf{h}$ MPpretreated group showing mild Bax expression and extensive Bcl-2 expression respectively. $\mathbf{i}$ and $\mathbf{j}$ Quantitative image analysis for immunohistochemical staining of Bax and Bcl-2 respectively expressed as optical densities (OD) across 10 different fields for each rat section. $\mathbf{k}$ The ratio of Bax to $\mathrm{BCl}-2$ expression in the heart of different groups. Data are presented as mean $\pm \mathrm{SD}(n=10)$; a or b: significantly different from control or ISO groups respectively at $P<0.05$ using one-way ANOVA followed by Tukey as post hoc test. MP methyl palmitate, ISO isoproterenol, Bax BCl-2-associated X, Bcl-2 B cell lymphoma 2

Catecholamines produce excessive amounts of free radicals inducing myocardial injury, due to their transformation into aminochromes, which undergo redox cycling in mitochondria resulting in the production of profuse amounts of oxygen-derived free radicals leading to loss of myocardial membranes function and integrity [40]. Herein the present study, ISO-intoxicated rats exhibited severe oxidative damage evidenced by the significant elevation in cardiac content of malondialdehyde (MDA), the lipid peroxidation product, and the marked reduction of the antioxidant defenses reduced glutathione (GSH) and superoxide dismutase (SOD) enzyme. These oxidative stress insults were previously reported in ISO intoxication models [30, 39]. On the contrary, MP pretreatment showed effective protection against ISO-induced oxidative insults evidenced by diminishing of MDA content and restoring of both GSH content and SOD activity. In this regard, MP had been proven to possess potent antioxidant capabilities [27, 41].

Endothelial nitric oxide synthase (eNOS) enzyme has major roles in the regulation of the vascular tone and providing marked cardioprotection against ischemic damage through the production of nitric oxide (NO) which is a potent vasodilator [11]. In the present study, ISO intoxication caused a marked reduction in the cardiac content of eNOS enzyme, which is consistent with previous studies that reported the diminished eNOS activity in experimental models of myocardial injury following ISO intoxication [6]. In contrast, MP pretreatment showed marked conserving of eNOS content within the myocardium. This implies that MP possesses promising vasodilator properties. These findings were in agreement with previous reports which proved that MP can induce aortic vasodilation and offer neuroprotection against cerebral ischemia where it diminished tissue necrosis and neuronal cell death caused by middle cerebral artery occlusion in the rat [42].

The free radicals evoked by ISO damage the mitochondrial membrane phospholipids resulting in loss of membrane potential stimulating caspase 3 to initiate cardiomyocytes' apoptotic degradation [13]. The mitochondrial membrane potential is mainly regulated by the proapoptotic proteins such as Bcl-2-associated X (Bax) and the anti-apoptotic proteins such as B cell lymphoma 2 (Bcl-2) [14]. Translocation of Bax to the outer mitochondrial membrane is believed to open the mitochondrial voltage-dependent anion channel leading to increased mitochondrial permeability [43]. Meanwhile, $\mathrm{Bcl}-2$ plays a critical role in the conserving of mitochondrial membrane integrity and stability [44].

Herein the present study, ISO intoxication elicited an apoptotic cell death in the cardiac tissues as it increased the expression of the pro-apoptotic markers Bax and caspase 3 and diminished the expression of the anti- 


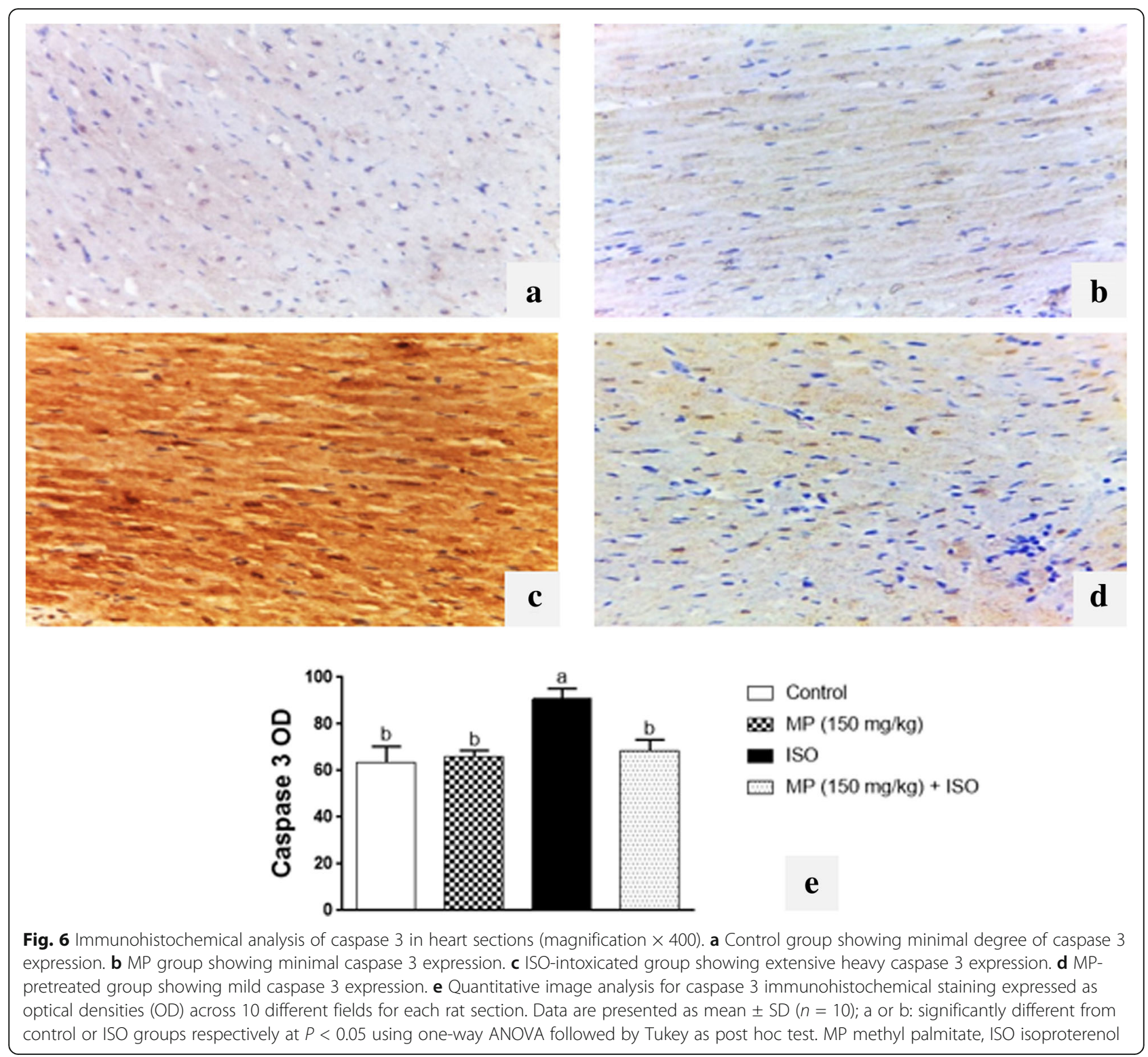

apoptotic marker $\mathrm{Bcl}-2$. Moreover, calculating the ratio of $\mathrm{Bax} / \mathrm{Bcl}-2$ showed elevated ratios in ISO-intoxicated group confirming the apoptotic effects of ISO. These effects were in agreement with previous studies that reported the crucial role of apoptotic events in the pathophysiology of ISO-induced myocardial injury [13, 20]. On the other hand, pretreatment of the rats with MP prevented the apoptotic effects of ISO as evidenced by downregulating the apoptotic proteins Bax and caspase 3 expressions while upregulating $\mathrm{Bcl}-2$ expression. In this regard, MP had been reported to have potent antiapoptotic effects in different experimental models via reducing Bax/Bcl-2 ratio [45].

Necrosis plays vital roles in cardiomyocyte death especially during the initial ischemic insult [46]. The necrotic tissue injury is associated with the release of various intracellular components that called danger-associated molecular patterns (DAMPs) [17, 47]. The pattern recognition receptors (PRRs), the main molecules of the innate immune system, recognize these DAMPs hence switching on several inflammatory cascades [48].

Among PRRs, toll-like receptors (TLRs) that have cardinal roles in mediating myocardial inflammation are engaged by DAMPs activating many inflammatory responses [49]. Toll-like receptor 4 (TLR-4), whose the highest expression in cardiac tissues as compared to the other TLRs, plays a pivotal role in the pathogenesis of multiple cardiovascular disorders [50]. Upon TLR-4 stimulation, intracellular adaptor proteins are recruited to the signaling complex and stimulate downstream cascades [50, 51]. Myeloid differentiation primary response protein (MyD88) is the first and the most critical 


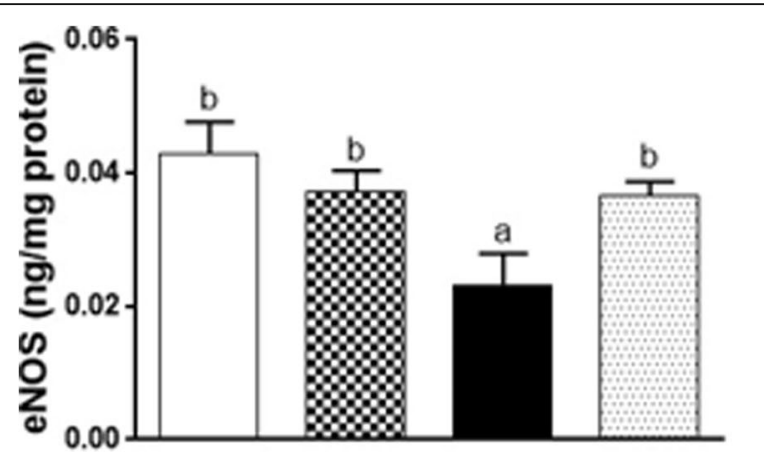

\section{Control \\ $\otimes$ MP (150 mg/kg) \\ ISO \\ MP $(150 \mathrm{mg} / \mathrm{kg})+$ ISO}

$\mathbf{a}$

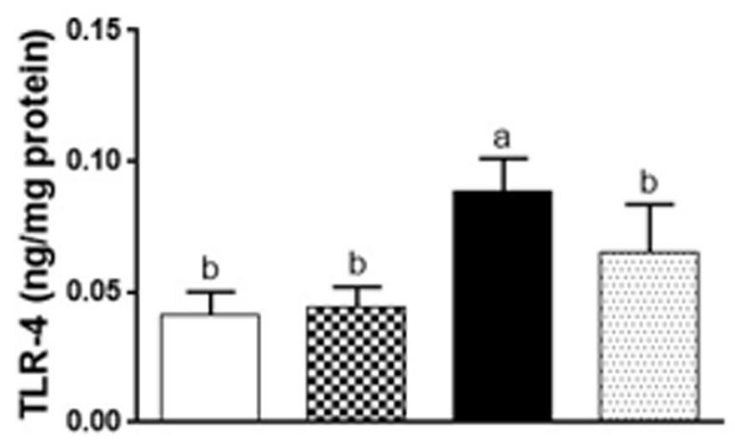

$\square$ Control

\& MP (150 mg/kg)

- ISO

$\square M P(150 \mathrm{mg} / \mathrm{kg})+$ ISO

b

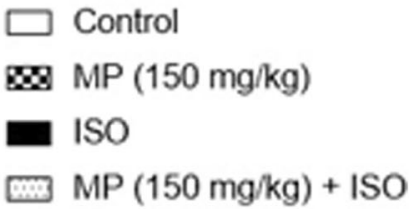

c

Fig. 7 Effect of MP $(150 \mathrm{mg} / \mathrm{kg})$ on cardiac content of eNOS, TLR-4, and TNF-a in ISO-intoxicated rats. a eNOS. b TLR-4. c TNF-a. Rats were pretreated with MP (150 mg/kg, p.o) three times per week on alternating days for 2 weeks and then injected with 2 consecutive doses of ISO (85 $\mathrm{mg} / \mathrm{kg}, \mathrm{s} . \mathrm{c})$ on the 13th and 14th days. Data are presented as mean \pm SD $(n=7)$; a or b: significantly different from control or ISO groups respectively at $P<0.05$ using one-way ANOVA followed by Tukey as a post hoc test. MP methyl palmitate, ISO isoproterenol, eNOS endothelial nitric oxide synthase, TLR-4 toll-like receptor 4, TNF-a tumor necrosis factor alpha

adaptor protein that recruited to the signaling complex resulting in the activation of downstream pathways culminating in nuclear factor kappa B (NF-kB) activation [52]. Notably, NF-kB is the ubiquitous transcriptional factor that regulates the expression of numerous proinflammatory mediators such as tumor necrosis factoralpha (TNF- $\alpha)$ and cyclooxygenase-2 (COX-2) enzyme [53]. In quiescent cells, NF-kB is inhibited by interacting with the inhibitory kappa B $(\mathrm{IkB})$ protein in the cytoplasm [54]. Upon NF-kB activation, it translocates into the nucleus where it upregulates the gene expression of numerous pro-inflammatory cytokines [55].

In the current study, ISO intoxication elicited amplified inflammatory responses in the myocardium as evidenced by the increased cardiac contents of TLR-4 and TNF- $\alpha$ cytokine. Besides, the expression of the transcription factor NF-kB and COX-2 enzyme was also upregulated in ISO-intoxicated rats. These findings are in agreement with former studies that proved the inflammatory insults induced by ISO $[5,56]$. In this context, previous studies have demonstrated that the elevated expression of TLR-4 mediates adverse ventricular remodeling following myocardial injury in animal models via boosting inflammatory and fibrotic processes [26]. On the other hand, MP pretreatment effectively abolished all these inflammatory signals as shown by the marked reduction in the cardiac contents of TLR- 4 and TNF- $\alpha$ in addition to the significant reduction in the cardiac 

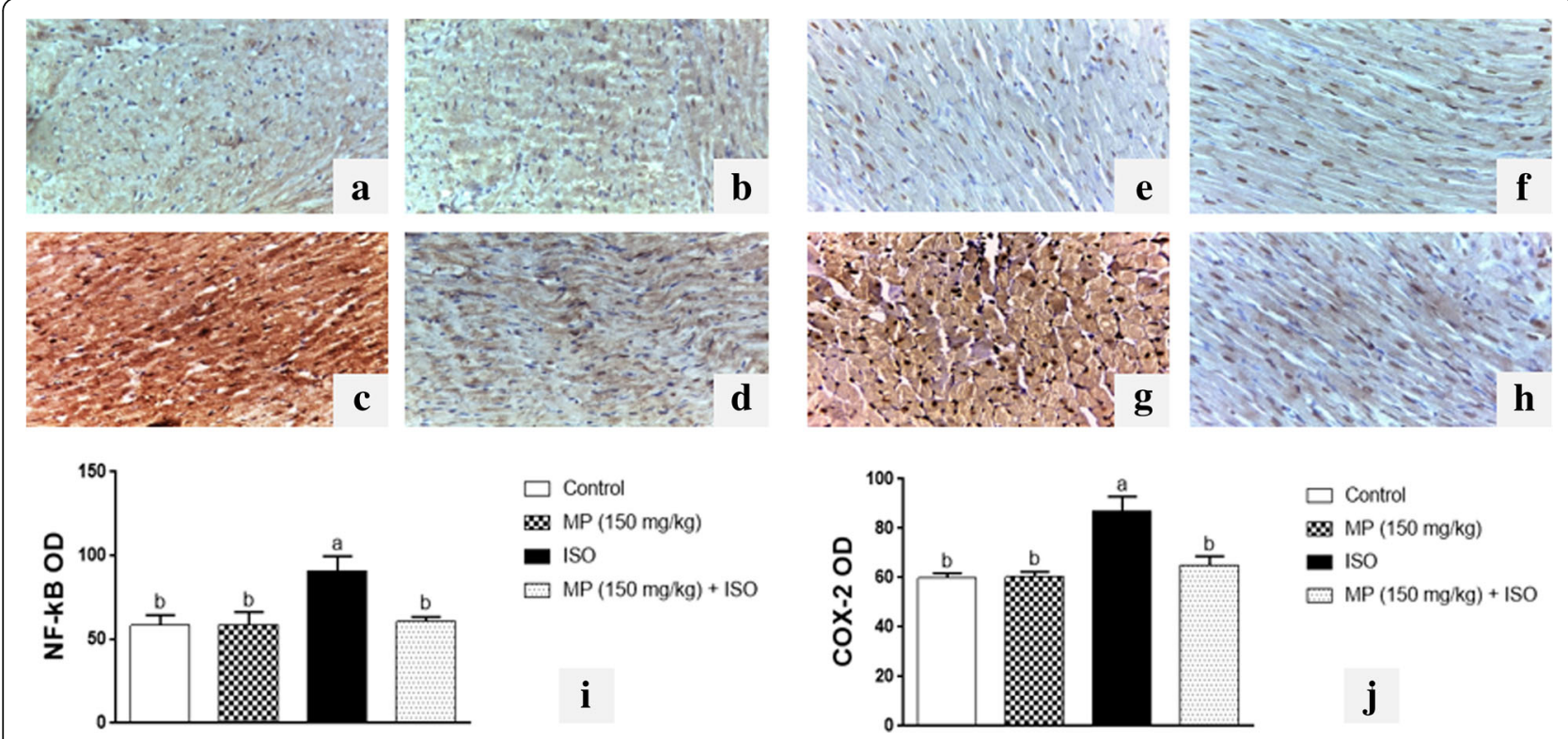

Fig. 8 Immunohistochemical analysis of NF-kB and COX-2 in heart sections (magnification $\times 400$ ). a and e Control group showing normal architecture with minimal expression of NF-kB and COX-2 respectively. $\mathbf{b}$ and $\mathbf{f}$ MP group showing minimal expression of NF-kB and COX-2 respectively. $\mathbf{c}$ and $\mathbf{g}$ ISO-intoxicated group showing extensive heavy expression of NF-kB and COX-2 respectively. $\mathbf{d}$ and $\mathbf{h}$ MP-pretreated group showing mild expression of NF-kB and COX-2 respectively. $\mathbf{i}$ and $\mathbf{j}$ Quantitative image analysis for immunohistochemical staining of NF-kB and COX-2 respectively expressed as optical densities (OD) across 10 different fields for each rat section. Data are presented as mean \pm SD $(n=10) ;$ a or b: significantly different from control or ISO groups respectively at $P<0.05$ using one-way ANOVA followed by Tukey as post hoc test. MP methyl palmitate, ISO isoproterenol, NF-kB nuclear factor kappa B, COX-2 cyclooxygenase 2

expression of NF-kB and COX-2 proteins. These results point out the anti-inflammatory properties of MP, which help in its cardioprotective effects besides its antioxidant, anti-apoptotic, and vasodilatation activities. In this context, the anti-inflammatory effects of MP were reported in former studies [24, 25]. Additionally, it was reported that MP mitigated cyclophosphamide-induced cardiotoxicity via suppressing the TLR-4/NF-kB signaling pathway [26].

\section{Conclusion}

The present study elucidated for the first time the cardioprotective role of MP against ISO-induced myocardial injury in rats. The main mechanisms underlying this cardioprotective effect were abrogating TLR-4/NF-kB inflammatory pathway, enhancing cardiac eNOS content and the potent antioxidant and anti-apoptotic activities of MP. Thus, pretreatment with MP could provide a new promising solution for the protection against myocardial injury. Additional studies may be performed for further elucidation of the other mechanism(s) of the beneficial effects of MP in this model.

\section{Abbreviations}

AST: Aspartate aminotransferase; Bax: Bcl-2-associated X; Bcl-2: B cell lymphoma 2; BSA: Bovine serum albumin; CK-MB: Creatine kinase myocardial band; COX-2: Cyclooxygenase-2; DAMPs: Damage-associated molecular patterns; ECG: Electrocardiography; eNOS: Endothelial nitric oxide synthase;
GSH: Reduced glutathione; H\&E: Hematoxylin and eosin; IkB: Inhibitory kappa B; ISO: Isoproterenol; LDH: Lactate dehydrogenase; MDA: Malondialdehyde; MP: Methyl palmitate; MyD88: Myeloid differentiation primary response protein; NF-kB: Nuclear factor kappa B; PRRs: Pattern recognition receptors; ROS: Reactive oxygen species; SOD: Superoxide dismutase; TBS: Tris-buffered saline; TLR-4: Toll-like receptor 4; TLRs: Toll-like receptors; TNF-a: Tumor necrosis factor-alpha

\section{Acknowledgements}

Not applicable for that section

\section{Authors' contributions}

$\mathrm{AH}$ : conception and design, acquisition of data, analysis and interpretation of data, drafting the article, and revised and approved the final version of the manuscript. EM: conception and design, acquisition of data, analysis and interpretation of data, drafting the article, and revised and approved the final version of the manuscript. WE: acquisition of data, analysis and interpretation of data, and revised and approved the final version of the manuscript. YA: conception and design; analysis and interpretation of data; and edited, revised, and approved the final version of the manuscript. SA: conception and design; analysis and interpretation of data; and edited, revised, and approved the final version of the manuscript. All authors read and approved the final manuscript.

\section{Funding}

This research did not receive any specific grant from funding agencies in the public, commercial, or not-for-profit sectors.

\section{Availability of data and materials}

All data and materials are available upon request.

\section{Ethics approval and consent to participate}

All procedures and manipulations of experimental animals were carried out according to the ARRIVE guidelines and in accordance with UK Animals Act, 1986, and approved by the Research Ethics Committee for experimental and 
clinical studies of Faculty of Pharmaceutical Sciences and Pharmaceutical Industries, Future University in Egypt, under the memorandum No.: (RECFPSPI-9/60).

\section{Consent for publication}

Not applicable for that section

\section{Competing interests}

The authors declare that they have no competing interests.

\section{Author details}

${ }^{1}$ Pharmacology, Toxicology and Biochemistry Department, Faculty of Pharmaceutical Sciences and Pharmaceutical Industries, Future University in Egypt, End of 90th St., 5th Settlement, New Cairo, Cairo 11835, Egypt. ${ }^{2}$ Pharmacology and Toxicology Department, Faculty of Pharmacy, Ain shams University, Cairo, Egypt. ${ }^{3}$ Pharmacology and Therapeutics Department, Faculty of Medicine, Ain Shams University, Cairo, Egypt.

Received: 19 February 2020 Accepted: 10 June 2020

Published online: 09 July 2020

\section{References}

1. Ardjmand A, Shahaboddin ME, Mazoochi T, Heydari A, Ghavipanjeh G (2019) Cardioprotective effects of cerebrolysin on the lesion severity and inflammatory factors in a rat model of isoproterenol-induced myocardial injury. Pharmacol Rep 71:682-687. https://doi.org/10.1016/j.pharep.2019.03. 003

2. Karlsson LO, Bergh N, Li L, Bissessar E, Bobrova I, Gross GJ, Akyürek LM, Grip $L$ (2012) Dose-dependent cardioprotection of enkephalin analogue eribis peptide 94 and cardiac expression of opioid receptors in a porcine model of ischaemia and reperfusion. Eur J Pharmacol 674:378-383. https://doi.org/ 10.1016/j.ejphar.2011.11.012

3. Lobo RO, Sagar BC, Shenoy CK (2017) Bio-tea prevents membrane destabilization during isoproterenol-induced myocardial injury. J Microsc Ultrastruct 5:146-154. https://doi.org/10.1016/j.jmau.2016.09.001

4. Reisner E, Reisner H (2016) Crowley's an introduction to human disease. Jones \& Bartlett, Massachusetts

5. Shahzad S, Mateen S, Naeem SS, Akhtar K, Rizvi W, Moin S (2019) Syringic acid protects from isoproterenol induced cardiotoxicity in rats. Eur $\mathrm{J}$ Pharmacol 849:135-145. https://doi.org/10.1016/j.ejphar.2019.01.056

6. Attalla DM, Ahmed LA, Zaki HF, Khattab MM (2018) Paradoxical effects of atorvastatin in isoproterenol-induced cardiotoxicity in rats: role of oxidative stress and inflammation. Biomed Pharmacother 104:542-549. https://doi. org/10.1016/j.biopha.2018.05.005

7. Zhao L, Wu D, Sang M, Xu Y, Liu Z, Wu Q (2017) Stachydrine ameliorates isoproterenol-induced cardiac hypertrophy and fibrosis by suppressing inflammation and oxidative stress through inhibiting NF-kappaB and JAK STAT signaling pathways in rats. Int Immunopharmacol 48:102-109. https:// doi.org/10.1016/j.intimp.2017.05.002

8. Badore NS, Das PK, Pillai S (2017) Pharmacological efficacy of methanolic extract of the plant ginkgo biloba against isoproterenol induced cardiac toxicity in rats. Int J Pharm Sci Drug Res 8:722-728. https://doi.org/10.13040/ IJPSR.0975-8232.8(2).722-28

9. Cai H, Harrison DG (2000) Endothelial dysfunction in cardiovascular diseases: the role of oxidant stress. Circ Res 87:840-844. https://doi.org/10.1161/01.res. 87.10 .840

10. Ahmed Z, Tang WW (2012) Pharmacologic strategies to target oxidative stress in heart failure. Curr Heart Fail Rep 9:14-22. https://doi.org/10.1007/ s11897-011-0081-5

11. Jones SP, Bolli R (2006) The ubiquitous role of nitric oxide in cardioprotection. J Mol Cell Cardiol 40:16-23. https://doi.org/10.1016/j.yjmcc. 2005.09.011

12. Pelat M, Massion P, Balligand JL (2005) Nitric oxide "at heart": emerging paradigms after a decade. Arch Mal Coeur Vaiss 98:242-248

13. Suchal K, Malik S, Gamad N, Malhotra RK, Goyal SN, Bhatia J, Arya DS (2016) Kampeferol protects against oxidative stress and apoptotic damage in experimental model of isoproterenol-induced cardiac toxicity in rats. Phytomedicine 23:1401-1408. https://doi.org/10.1016/j.phymed.2016.07.015

14. Ol KK, Kanbak G, Illhan AO, Kartkaya K, Inal ME (2017) Morinda citrifolia (noni) and low dose aspirin prevent apoptotic cell death and oxidative stress on isoproterenol induced myocardial infarction in rats. Erciyes Med J 39:165170. https://doi.org/10.5152/etd.2017.1732

15. Prabhu SD, Wang G, Luo J, Gu Y, Ping P, Chandrasekar B (2003) $\beta$ Adrenergic receptor blockade modulates $\mathrm{BCl}$-XS expression and reduces apoptosis in failing myocardium. J Mol Cell Cardiol 35:483-493. https://doi. org/10.1016/S0022-2828(03)00052-X

16. D'amico R, Fusco R, Gugliandolo E, Cordaro M, Siracusa R, Impellizzeri D, Peritore AF, Crupi R, Cuzzocrea S, Di Paola R (2019) Effects of a new compound containing palmitoylethanolamide and baicalein in myocardial ischaemia/reperfusion injury in vivo. Phytomedicine 54:27-42. https://doi. org/10.1016/j.phymed.2018.09.191

17. Timmers L, Pasterkamp G, de Hoog VC, Arslan F, Appelman Y, de Kleijn DP (2012) The innate immune response in reperfused myocardium. Cardiovasc Res 94:276-283. https://doi.org/10.1093/cvr/cvs018

18. Turner NA (2016) Inflammatory and fibrotic responses of cardiac fibroblasts to myocardial damage associated molecular patterns (DAMPs). J Mol Cell Cardiol 94:189-200. https://doi.org/10.1016/j.yjmcc.2015.11.002

19. Younis NS, Mohamed ME (2019) $\beta$-Caryophyllene as a potential protective agent against myocardial injury: the role of toll-like receptors. Molecules 24: 1929-1944. https://doi.org/10.3390/molecules24101929

20. Khan V, Sharma S, Bhandari U, Sharma N, Rishi V, Haque SE (2019) Suppression of isoproterenol-induced cardiotoxicity in rats by raspberry ketone via activation of peroxisome proliferator activated receptor-a. Eur J Pharmacol 842:157-166. https://doi.org/10.1016/j.ejphar.2018.10.034

21. Lin HW, Liu CZ, Cao D, Chen PY, Chen MF, Lin SZ, Mozayan M, Chen AF, Premkumar LS, Torry DS (2008) Endogenous methyl palmitate modulates nicotinic receptor-mediated transmission in the superior cervical ganglion. Proc Natl Acad Sci 105:19526-19531. https://doi.org/10.1073/pnas. 0810262105

22. Lee YC, Chang HH, Liu CH, Chen MF, Chen PY, Kuo JS, Lee TJF (2010) Methyl palmitate: a potent vasodilator released in the retina. Invest Ophthalmol Vis Sci 51:4746-4753. https://doi.org/10.1167/iovs.09-5132

23. Kalemci S, Sarihan A, Dere Y (2018) Methyl palmitate protection against isoniazide/rifampisicin-induced oxidative liver damage. Iran Red Crescent Med J 20:e60819. https://doi.org/10.5812/ircmj.60819

24. Saeed NM, El-Demerdash E, Abdel-Rahman HM, Algandaby MM, Al-Abbasi FA, Abdel-Naim AB (2012) Anti-inflammatory activity of methyl palmitate and ethyl palmitate in different experimental rat models. Toxicol Appl Pharmacol 264:84-93. https://doi.org/10.1016/j.taap.2012.07.020

25. El-Demerdash E (2011) Anti-inflammatory and antifibrotic effects of methyl palmitate. Toxicol Appl Pharmacol 254:238-244. https://doi.org/10.1016/j. taap.2011.04.016

26. El-Agamy DS, Elkablawy MA, Abo-Haded HM (2017) Modulation of cyclophosphamide-induced cardiotoxicity by methyl palmitate. Cancer Chemother Pharmacol 79:399-409. https://doi.org/10.1007/s00280-0163233-1

27. Mantawy EM, Tadros MG, Awad AS, Hassan DA, El-Demerdash E (2012) Insights antifibrotic mechanism of methyl palmitate: impact on nuclear factor kappa B and proinflammatory cytokines. Toxicol Appl Pharmacol 258: 134-144. https://doi.org/10.1016/j.taap.2011.10.016

28. Lee YC, Chang HH, Chiang CL, Liu CH, Yeh Jl, Chen MF, Chen PY, Kuo JS, Lee TJ (2011) Role of perivascular adipose tissue-derived methyl palmitate in vascular tone regulation and pathogenesis of hypertension. Circulation 124:1160-1171. https://doi.org/10.1161/circulationaha.111.027375

29. Directive C (1986) 86/609/EEC of 24 November 1986 on the approximation of laws, regulations and administrative provisions of the member states regarding the protection of animals used for experimental and other scientific purposes. Off J Eur Commun 29:L358

30. Acikel M, Buyukokuroglu ME, Erdogan F, Aksoy H, Bozkurt E, Senocak H (2005) Protective effects of dantrolene against myocardial injury induced by isoproterenol in rats: biochemical and histological findings. Int J Cardiol 98: 389-394. https://doi.org/10.1016/j.ijcard.2003.10.054

31. Shaikh S, Bhatt LK, Barve K (2019) Attenuation of isoproterenol-induced cardiotoxicity in rats by narirutin rich fraction from grape fruit. Phytomedicine 55:222-228. https://doi.org/10.1016/j.phymed.2018.06.037

32. Katare PB, Bagul PK, Dinda AK, Banerjee SK (2017) Toll-like receptor 4 inhibition improves oxidative stress and mitochondrial health in isoproterenol-induced cardiac hypertrophy in rats. Front Immunol 8:719729. https://doi.org/10.3389/fimmu.2017.00719

33. Murugesan S, Pandiyan A, Saravanakumar L, Moodley K, Mackraj I (2019) Protective role of wild garlic on isoproterenol-induced myocardial necrosis 
in wistar rats. J Ethnopharmacol 237:108-115. https://doi.org/10.1016/j.jep. 2019.03.049

34. Sørensen LL, Bedja D, Sysa-Shah P, Liu H, Maxwell A, Yi X, Pozios I, Olsen NT, Abraham TP, Abraham R (2016) Echocardiographic characterization of a murine model of hypertrophic obstructive cardiomyopathy induced by cardiac-specific overexpression of epidermal growth factor receptor 2. Comp Med 66:268-277. doi: $\mathrm{cm} /$ 2016/00000066/00000004/art00001.

35. Wang H, Cao C, Hui L, Liu T, Wang Y, Gao S, Zhang Y, Hao R, Li C, Zang C (2016) A study of myocardial ischemia model induced by left coronary artery ligation in rats. World J Cardiovasc Dis 6:133-142. https://doi.org/10. 4236/wjcd.2016.65014

36. Mazzoleni A, Curtin ME, Wolff R, Reiner L, Somes G (1975) On the relationship between heart weights, fibrosis, and QRS duration. J Electrocardiol 8:233-236. https://doi.org/10.1016/S0022-0736(75)80050-1

37. Abbas AM (2016) Cardioprotective effect of resveratrol analogue isorhapontigenin versus omega-3 fatty acids in isoproterenol-induced myocardial infarction in rats. J Physiol Biochem 72:469-484. https://doi.org/ 10.1007/s13105-016-0494-4

38. Metias E, Aboelmaaty N, Hussein A, Abdallah E, Abdelaziz A (2016) Modulation of ECG, myocardial oxidative stress markers and connexion 43 expression by ascorbic acid and ferulic acid in isoproterenol-induced myocardial infarction in rats. Biochem Physiol 5:210-219. https://doi.org/10. 4172/2168-9652.1000210

39. Panda S, Kar A, Biswas S (2017) Preventive effect of agnucastoside C against isoproterenol-induced myocardial injury. Sci Rep 7:16146-16159. https://doi. org/10.1038/s41598-017-16075-0

40. Pullaiah CP, Kumar GN, Jyothsna K, Thyagaraju K, Nelson VK, Reddy GD (2017) Rosa damascena mill. L. Attenuates myocardial lysosomal membrane destabilization in isoproterenol induced oxidative stress. Orient Pharm Exp Med 17:373-380. https://doi.org/10.1007/s13596-017-0290-x

41. Ammar EM, Sharawy MH, Shalaby AA, El-Agamy DS (2013) Effects of methyl palmitate and lutein on LPS-induced acute lung injury in rats. World J Respirol 3:20-28. https://doi.org/10.5320/wjr.v3.i2.20

42. Lin HW, Saul I, Gresia VL, Neumann JT, Dave KR, Perez-Pinzon MA (2014) Fatty acid methyl esters and solutol HS 15 confer neuroprotection after focal and global cerebral ischemia. Transl Stroke Res 5:109-117. https://doi. org/10.1007/s12975-013-0276-z

43. Shi Y, Chen J, Weng C, Chen R, Zheng Y, Chen Q, Tang H (2003) Identification of the protein-protein contact site and interaction mode of human VDAC1 with Bcl-2 family proteins. Biochem Biophys Res Commun 305:989-996. https://doi.org/10.1016/S0006291X(03)00871-4

44. Gross A, Katz SG (2017) Non-apoptotic functions of BCL-2 family proteins. Cell Death Differ 24:1348-1358. https://doi.org/10.1038/cdd.2017.22

45. Arab HH, Salama SA, Eid AH, Kabel AM, Shahin NN (2019) Targeting MAPKs, $\mathrm{NF}-\mathrm{KB}$, and PI3K/AKT pathways by methyl palmitate ameliorates ethanolinduced gastric mucosal injury in rats. J Cell Physiol 234:22424-22438. https://doi.org/10.1002/jcp.28807

46. Liu L, Cui J, Yang Q, Jia C, Xiong M, Ning B, Du X, Wang P, Yu X, Li L (2014) Apocynin attenuates isoproterenol-induced myocardial injury and fibrogenesis. Biochem Biophys Res Commun 449:55-61. https://doi.org/10. 1016/j.bbrc.2014.04.157

47. Arslan F, De Kleijn DP, Pasterkamp G (2011) Innate immune signaling in cardiac ischemia. Nat Rev Cardiol 8:292-300. https://doi.org/10.1038/ nrcardio.2011.38

48. Bianchi ME (2007) DAMPs, PAMPs and alarmins: all we need to know about danger. J Leukoc Biol 81:1-5. https://doi.org/10.1189/jlb.0306164

49. Takeuchi O, Akira S (2010) Pattern recognition receptors and inflammation. Cell 140:805-820. https://doi.org/10.1016/j.cell.2010.01.022

50. Yang Y, Lv J, Jiang S, Ma Z, Wang D, Hu W, Deng C, Fan C, Di S, Sun Y (2017) The emerging role of toll-like receptor 4 in myocardial inflammation. Cell Death Dis 7:e2234. https://doi.org/10.1038/cddis.2016.140

51. Gay NJ, Symmons MF, Gangloff M, Bryant CE (2014) Assembly and localization of toll-like receptor signalling complexes. Nat Rev Immunol 14 546-558. https://doi.org/10.1038/nri3713

52. Soraya H, Farajnia S, Khani S, Rameshrad M, Khorrami A, Banani A, Maleki DN, Garjani A (2012) Short-term treatment with metformin suppresses toll like receptors (TLRs) activity in isoproterenol-induced myocardial infarction in rat: are AMPK and TLRs connected? Int Immunopharmacol 14:785-791. https://doi.org/10.1016/j.intimp.2012.10.014
53. Hoffmann A, Natoli G, Ghosh G (2006) Transcriptional regulation via the NFKB signaling module. Oncogene 25:6706-6716. https://doi.org/10.1038/sj. onc.1209933

54. Kaufman PA, Weinberg JB, Greene WC (1992) Nuclear expression of the 50and $65-\mathrm{kD}$ Rel-related subunits of nuclear factor-kappa B is differentially regulated in human monocytic cells. J Clin Invest 90:121-129. https://doi. org/10.1172/JCl115824

55. Diomede F, Zingariello M, Cavalcanti MF, Merciaro I, Pizzicannella J, Deisla N, Caputi S, Ballerini P, Trubiani O (2017) MyD88/ERK/NFkB pathways and proinflammatory cytokines release in periodontal ligament stem cells stimulated by Porphyromonas gingivalis. Eur J Histochem 61:112-117. https://doi.org/10.4081/ejh.2017.2791

56. Eladwy RA, Mantawy EM, El-Bakly WM, Fares M, Ramadan LA, Azab SS (2018) Mechanistic insights to the cardioprotective effect of blueberry nutraceutical extract in isoprenaline-induced cardiac hypertrophy. Phytomedicine 51:84-93. https://doi.org/10.1016/j.phymed.2018.10.009

\section{Publisher's Note}

Springer Nature remains neutral with regard to jurisdictional claims in published maps and institutional affiliations.

\section{Submit your manuscript to a SpringerOpen ${ }^{\circ}$ journal and benefit from:}

- Convenient online submission

- Rigorous peer review

- Open access: articles freely available online

- High visibility within the field

- Retaining the copyright to your article

Submit your next manuscript at $\boldsymbol{\nabla}$ springeropen.com 